\title{
MOURNING DOVE DISPLAY ELICITED BY A RED SQUIRREL
}

ROBERT W. NERO, Wildlife Branch, 1945 St. James Street, Winnipeg, Manitoba. R3H OW9

Bird feeders often provide an opportunity to view wild birds and a few mammals at close range and over extended periods. Interactions between individual birds and different species occur daily; aggressive and submissive displays are a common sight. At our feeders, Red Squirrels are the dominant visitors, displacing with spirited vigor all birds and the occasional larger Grey Squirrel.

It was with some surprise, therefore, that I observed an adult Mourning Dove holding a position close to an adult Red Squirrel. This event took place on 28 May 1985 between 5:28-5:33 p.m. A patch of spilled mixed seeds on the grass beneath a feeder attached to a tree $9 \mathrm{~m}$ (30 feet) from our house had attracted a dove and a squirrel. When I first noticed them they were facing each other; the squirrel was feeding in the patch, the dove was off to one side about $50 \mathrm{~cm}$ (20 in.) away. The dove appeared reluctant to advance to feed or to leave; it was crouching down with all its feathers fluffed out, remaining still. When the squirrel advanced a few inches and sat up to gnaw on a sunflower seed in its paws, the dove briefly raised both wings to full length straight overhead and touching, an unexpected display, but it held its ground.

The squirrel advanced again to about 40 $\mathrm{cm}$ (16 in.), sitting up and feeding, whereupon the dove raised its right wing fully extended upwards and slightly tipped over its back to its left side. The dove occasionally pecked at the ground (displacement feeding?). The dove repeated this one-wing display, again without backing away from the squirrel.
When the squirrel moved back to the base of the tree, the dove at once advanced a few inches, pecking at the ground, but not yet actually feeding. Suddenly, as if releasing nervous tension, the dove fanned out its tail feathers and raised its folded wings upward, briefly stretching hard.

Finally, the squirrel ran up the tree and away. Immediately the dove walked into the food patch and fed rapidly. A male Common Grackle that came walking by failed to move the dove, but when four House Sparrows flew off they momentarily startled the dove, which then resumed feeding.

The dove's initial posture with feathers raised and breast lowered can be identified as a component of a generalized defensive display ("including erected feathers, glaring eye, snapping bill, and low hiss") seen in many birds; it is part of an "expression of fear" seen in a "bird which for one reason or another, must stay in its place and meet the danger.... It is exhibited by the Mourning Dove with the usual intensity. ${ }^{1}$ Extensive descriptions of Mourning Dove behaviour, however, give no mention of an elevated wing(s) display. ${ }^{2} 2$ Lack of observation of an elevated wing(s) display in the Mourning Dove suggests that this is not a regular display; certainly the close contact between a Mourning Dove and a Red Squirrel was an unusual situation. It seems likely that the observed postures of the Mourning Dove in this case arose out of a conflict of drives - an urge to flee, balanced with an urge to stay and feed.

A published account of an encounter 
between a nesting Band-tailed Pigeon and a Fox Squirrel is worth relating. "Defense of the nest against a possible predator was observed on June 4, at 11:55 a.m. A fox squirrel (Sciurus niger), while crossing a tree at nest level, noticed the incubating male. The squirrel at once climbed on to a limb above the pigeon and peered down at it. Then the squirrel dropped beneath the nest and sniffed at the latter from below. Finally it climbed to the nest limb and advanced toward the pigeon. When it had almost reached the bird, the latter half-raised himself, drooped his wings and bristled the lesser wing coverts. Then, opening its bill slightly, the pigeon hissed and struck out with the bends of its wings. The squirrel at once retreated and left the tree." ${ }^{\prime 3}$
I wish to thank Robert $E$. Jones for drawing my attention to the publications on the Mourning Dove and Band-tailed Pigeon.

1 CRAIG, W. 1911. The expressions of emotion in the pigeons. II. The Mourning Dove (Zenaidura macroura Linn.). Auk 28:398-407.

2 JACKSON, G.L. and T.S. BASKETT. 1964. Perch-cooing and other aspects of breeding behavior of Mourning Doves. Journ. Wildl. Mgt. 28:293-307.

${ }^{3}$ PEETERS, H.J. 1962. Nuptial behavior of the Band-tailed Pigeon in the San Francisco Bay area. Condor 64:445-470.

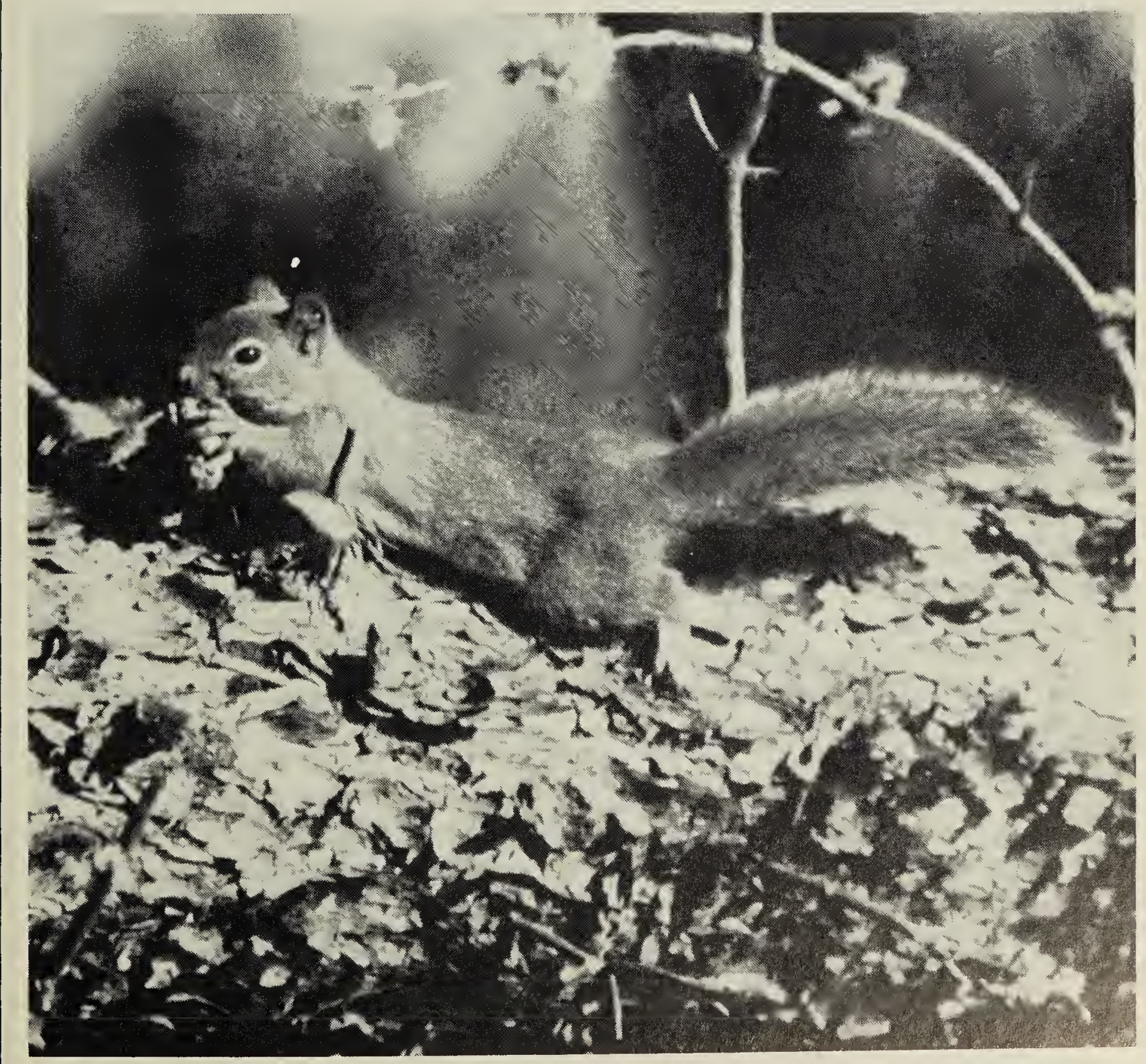

Red Squirrel

Fred Lahrman 